\title{
Acute non-puerperal uterine inversion: a case report in Madagascar
}

\author{
Todisoa M. Rakotomboahangy ${ }^{1}$, Hary F. Rabarikoto ${ }^{2 *}$, \\ Andriamanetsiarivo T. Ratsiatosika ${ }^{3}$, Hery R. Andrianampanalinarivo ${ }^{3}$
}

\begin{abstract}
${ }^{1}$ Department of Obstetrics and Gynecology, University Hospital Center Tanambao I Antsiranana, Madagascar
${ }^{2}$ Department of Obstetrics and Gynecology, Military Hospital Antsiranana, Madagascar

${ }^{3}$ Department of Obstetrics and Gynecology, University Hospital Center GOB, Antananarivo, Madagascar
\end{abstract}

Received: 29 March 2018

Accepted: 02 April 2018

\section{*Correspondence:}

Dr. Hary F. Rabarikoto,

E-mail: hrabarikoto@yahoo.com

Copyright: () the author(s), publisher and licensee Medip Academy. This is an open-access article distributed under the terms of the Creative Commons Attribution Non-Commercial License, which permits unrestricted non-commercial use, distribution, and reproduction in any medium, provided the original work is properly cited.

\section{ABSTRACT}

The acute non-puerperal uterine inversion is a rare gynecologic complication. It is a medical-surgical emergency. We report the case of a 46-years-old Malagasy woman who is admitted at emergency room with vaginal painful mass and vaginal heavy bleeding. Uterine inversion which is due to a fundic submucosal myoma was found on clinical examination. The management was surgical and done by an abdominal hysterectomy.

Keywords: Hysterectomy, Madagascar, Non-puerperal uterine inversion, Submucosal myoma

\section{INTRODUCTION}

Uterus inversion is a condition in which the uterus turns inside out; with prolapsed of the fundus through the cervix. In most cases, it is reported in postpartum. The acute non-puerperal uterine inversion (NPUI) is considered as a rare gynecologic complication. ${ }^{1}$ Its frequency is unknown. It can easily cause life-threatening hemorrhage and so is a medical-surgical emergency. ${ }^{2} \mathrm{We}$ aimed to report a case in malagasy woman insisting on the clinical diagnostic.

\section{CASE REPORT}

A 46 year-old Malagasy woman had 5 pregnancies: 3 children born by vaginal deliveries that the last was 9 years ago, and 2 spontaneous abortions before this last one. She was admitted to the gynecology emergency room at 5 a.m for important vaginal bleeding with ball sensation in intravaginal part. She did not have a previous pelvic pain nor a vaginal bleeding. Her illness story is summed up by a feeling of mass inside vagina, occurred during defecation 12 hours before her admission. It is followed by metrorrhagia, vaginal pain and acute urine retention.

The patient was hemodynamically unstable. The abdomen was supple but sensitive in epigastric region. A bladder globe was found. In gynecological examination, a protruding mass delivered by the cervix in the vulvar area was highlight (Figure 1). The mass was with an active bleeding.

Imaging exams were not available in emergency. The diagnosis of grade III uterine inversion had been made by clinical examination. Vaginal hysterectomy had been indicated after short explanation about the pathology to the patient. Then, laparotomy was done because of an uncontrolled bleeding during the ligation of the first uterine artery. Laparotomy discovered a uterus completely inverted in fingers of gloves. Hysterectomy was performed. The hemoglobin rate was $5 \mathrm{~g} / \mathrm{dl}$ and the patient received blood transfusion during the intervention. Pathologic report confirmed that the fundus 
of uterus has benign submucosal leiomyoma with degeneration.

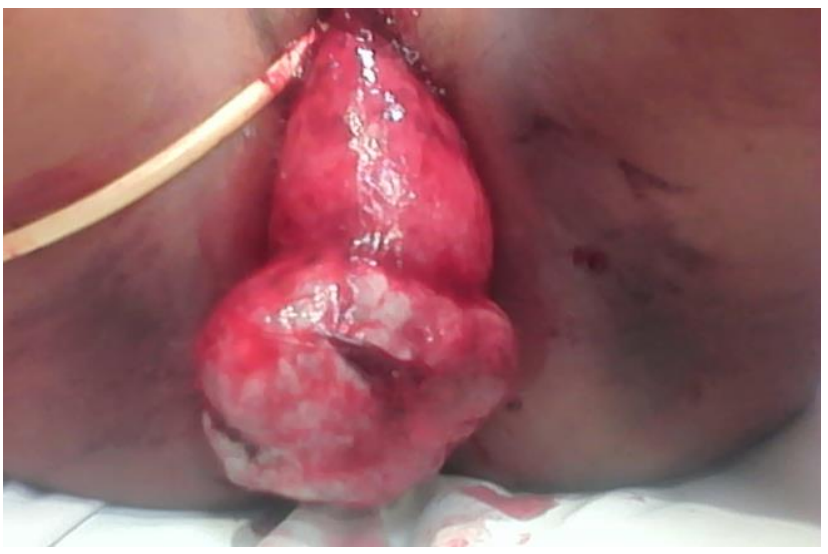

Figure 1: Protruding mass delivered by the cervix in the vulvar area.

\section{DISCUSSION}

The incidence of a NPUI is unknown. In a literature review published in 2005, Lupovitch et al had recorded only150 cases since $1887 .{ }^{3}$ Few gynecologists have observed it during their professional practice. ${ }^{4}$ This is the first reported case in our hospital.

Uterine inversion can be classified on four degrees according to the localization of the uterine fundus. In the first degree: the uterine fundus is still in the cavity and has not passed the cervix; in the 2nd degree: the fundus has passed the external orifice of the cervix; in the 3rd degree: the uterine fundus is externalized at the vulva; and in the 4th degree: the vaginal walls participate in the inversion. ${ }^{4}$

This pathology can be occurred in young women in full genital activity but in the majority of cases the incidence was observed in women above 45 years old. ${ }^{5,6}$

The NPUI is generally caused by an endocavity tumor which will provoke a traction force and causes the inversion. ${ }^{4}$ Those tumors can be a submucous myoma, a leiomyosarcoma, a rhabdomyosarcoma, a malignant mixed Mullerian tumour, and an endometrial polyp. ${ }^{7}$ But in literature, $85 \%$ of NPUI was caused by benign pathology and only in $15 \%$ of cases it was associated with cancer. ${ }^{5}$ In most of cases, it is due to a large submucous leiomyoma that leads to dilate cervix and protrude into vagina. ${ }^{1,8}$ The differential diagnosis are prolapsed myoma and endometrial polyp without inversion. ${ }^{9}$

In general practice, ultrasonography is the most modality evaluation, but it is inadequate to determine the exact nature of NPUI. MRI is the most performant examination to put diagnostic of NPIU and to make the differential diagnosis..$^{0,11}$
In our context of work, imaging exams are not available in emergency situations. Like for other authors, the diagnosis of NPUI is based on high index of suspicion. ${ }^{4,12}$ In the externalized forms, like in case that we report, the diagnosis seems easier by the visualization of the inverted uterus with submucosal myoma at the vulvar area. The absence of uterine fundus during abdominal palpation can confirm the diagnosis. In another type, a non-perception of the cervical orifice may be helpful. ${ }^{4}$ At the same time, the patient may have vaginal bleeding, pelvic pain and intermittent acute urinary retention. ${ }^{8,11}$

The definitive diagnosis is usually made at the time of hysterectomy by discovering a uterus inverted in fingers of gloves, in particular when the uterine inversion is not complete. $^{11}$

The choice of treatment is myomectomy or hysterectomy. When hysterectomy is not an option or when the future fertility is concerned, vaginal resection of submucous myomas can be considered before reducing the inversion. ${ }^{2,11}$ In the $3^{\text {rd }}$ degree, uterus reintegration may be difficult because of the constitution of a cervical neck ring. Vaginal myomectomy is also recommended as the initial treatment of choice. ${ }^{1}$ After that, hysterectomy can be performed vaginally or by abdominal surgery, depending on the operator's habits or surgical conditions. We managed our patient by laparotomy. Then we also decided hysterectomy because of her age, the degree of the NPUI, and her choice to not have children any more.

\section{CONCLUSION}

The NPUI is an exceptional pathology. Late management of the patient may cause life-threatening hemorrhage. The gynecologists must always have in mind the possibility of this complication in any mass delivered by the cervix. A well-lead clinical examination is very helpful to put diagnosis.

\section{Funding: No funding sources \\ Conflict of interest: None declared \\ Ethical approval: Not required}

\section{REFERENCES}

1. Kirbas A, Daglar K, Kara O, Sucak A, Caglar T. Non-puerperal uterine inversion due to submucous myoma in a woman: a case report. J Exp Ther Oncol. 2016;11(3):221-3.

2. Song YJ, Yang J, Yun HS, Lee SK, Kim HG, Lee DH et al. Non-puerperal Uterine Inversion Presented with Hypovolemic Shock. J Menopausal Med. 2016;22(3):184-7.

3. Lupovitch A, England ER, Chen R. Non-Puerperal Uterine Inversion in Association with Uterine Sarcoma: Case Report in a 26-Year-Old and Review of the Literature. Gynecologic Oncol. 2005;97:93841. 
4. Bohoussou E, Dia L, Yao I, Anzoua K, Guie P, Anongba S. Management of an unusual complication of uterine fibroids in the gynecological department of the university and hospital center of Treichville (Cote D'ivoire): about 2 cases of non-puerperal uterine inversion. Open $\mathrm{J}$ Obstet Gynecol. 2017;(7):220-5.

5. Mužná L, Pilka R. Uterine inversion. Ceska Gynekol 2017;82(2):139-44.

6. Kouamé A, Koffi SV, Adjoby R, Diomandé FA, Effoh D, Oussou C et al. Non-puerperal uterine inversion in a young woman: a case report. J West Afr Coll Surg. 2015;5(3):78-83.

7. Sakıncı M, Sanhal CY, İnayet Çelik G, Olgan Ş, Doğan NU. Uterine inversion as an extremely rare cause of secondary infertility: A case report. Turk $\mathbf{J}$ Obstet Gynecol. 2015;12( 1):50-52.

8. Teimoori B, Esmailzadeh A. A large uterine leiomyoma leading to non-puerperal uterine inversion: A case report. Int J Reprod Biomed. 2017;15(1):55-6.

9. Ali E, Kumar M. Chronic uterine inversion presenting as a painless vaginal mass at 6 months post partum: a case report. J Clin Diagn Res. 2016;10(5):QD07-8.

10. Mihmanli V, Kilic F, Pul S, Kilinc A, Kilickaya A. Magnetic resonance imaging of non-puerperal complete uterine inversion. Iran $\mathrm{J}$ Radiol. 2015;12(4):e9878.

11. Al Qahtani NH. Chronic incomplete non-puerperal uterine inversion due to huge submucous fibroid: diagnosis and management. BMJ Case Rep. 2018.

12. Umeononihu OS, Adinma JI, Obiechina NJ, Eleje GU, Udegbunam OI, Mbachu II. Uterine leiomyoma associated non-puerperal uterine inversion misdiagnosed as advanced cervical cancer: A case report. Int J Surg Case Rep. 2013;4(11):1000-3.

Cite this article as: Rakotomboahangy TM,

Rabarikoto HF, Ratsiatosika AT,

Andrianampanalinarivo HR. Acute non-puerperal uterine inversion: a case report in Madagascar. Int $\mathrm{J}$ Reprod Contracept Obstet Gynecol 2018;7:2023-5. 